\title{
O papel das formas urbanas na elaboração das políticas públicas de turismo da Amazônia paraense (Brasil)
}

\author{
The role of urban forms in the elaboration of public tourism policies in Amazonia \\ (Pará State, Brazil)
}

\author{
Hugo Hage Serra (SERRA, H. H.) ${ }^{*}$
}

\begin{abstract}
RESUMO - As políticas públicas de turismo são verdadeiros instrumentos de intervenção territorial. Não obstante, elas representam valores e ideias relacionados a uma finalidade e, sobretudo, estão associadas a um modo de pensamento espacial. No estado do Pará (Brasil), as políticas de turismo veiculam imagens, cenários e objetivos atrelados a uma maior circulação de capital na região. Um dos pontos basilares de análise dessas políticas de turismo são as formas espaciais tratadas em dois documentos importantes, tais como os planos de turismo. No estado do Pará, são dois os planos: Plano de Desenvolvimento do Turismo (PARÁ, 2001) e o Plano Ver-o-Pará de Desenvolvimento do Turismo (PARÁ, 2011). Por meio de uma metodologia que associa a crítica à produção do espaço turístico paraense e a análise do conteúdo dos planos, analisa-se neste texto o papel que as formas urbanas possuem quando veiculadas em políticas públicas de turismo no Pará, utilizando-se, para isso, a base do discurso geográfico na produção do território paraense.
\end{abstract}

Palavras-chave: Turismo; Políticas públicas de turismo; Formas espaciais urbanas; Planos de turismo; Estado do Pará.

ABSTRACT - Tourism Public Policies are authentic instruments of territorial intervention. In addition, they represent values and ideas related to a purpose and, above all, they are associated to a spatial mode of thought. In Pará State (Brazil), the tourism policies disseminate images, scenarios and goals linked to a greater circulation of capital in the region. One of the basic points of these tourism policies analysis are the spatial forms approached in two important documents, such as tourism plans. In Pará State there are two Tourism Plans: Tourism Development Plan (Pará 2001) and See Pará (Ver-o-Pará) Tourism Development Plan. Using a methodology that associates the criticism to the tourist space production of Pará and the contents plans analysis, this article analyzes the role that the urban forms has when they are transmitted in the tourism public policies, using for that matter the geographical discourse on territory production in this State.

Key words: Tourism; Tourism Public Policies; Urban Spatial Forms; Tourism Plans; Pará State.

\footnotetext{
* Formação: Graduação (Bacharelado e Licenciatura) em Geografia pela Universidade Federal do Pará (UFPA), mestrado em Geografia pelo Programa de Pós-Graduação em Geografia do Instituto de Filosofia e Ciências Humanas da UFPA, doutorado em Geografia pelo Programa de Pós-Graduação em Geografia da Faculdade de Ciências e Tecnologia da Universidade Estadual Paulista - UNESP - campus de Presidente Prudente. Atividade profissional: Professor de Geografia Regional - da Faculdade de Geografia - Instituto de Ciências Humanas - Universidade Federal do Sul e Sudeste do Pará (UNIFESSPA). Membro do Laboratório de Estudos Regionais e Agrários do Sul e Sudeste do Pará LERASSP. Endereço físico para correspondência: Qd. 7, Fl. 31, Lote Especial. Núcleo Nova Marabá, CEP: 68.507-590. Marabá - Pará/PA - Brasil. E-mail: hugorhserra@ gmail.com
} 


\section{INTRODUÇÃO}

Os estudos das formas urbanas estão na pauta das discussões geográficas ou daquelas que se inclinam a analisar a importância desse assunto como sendo fundamental para a compreensão do espaço geográfico. No século XX, por exemplo, o estudo desse tema serviu de suporte para aprofundamentos de métodos e das teorias que envolvem ideias sobre as cidades. Já se percebia, naquela época, que as formas urbanas não estavam restritas apenas à imagem no espaço - no sentido de um objeto - mas, por outro lado e de "forma" mais complexa, elas já demonstravam o sentido humano de sua existência. Daí, portanto, a necessidade de se estudar o papel que elas possuem na organização espacial, estabelecendo, por conseguinte, uma função social.

Partindo da ideia de que as formas espaciais são resultado (dentro de um contexto específico) das ações arquitetadas por pessoas organizadas individualmente ou coletivamente, pode-se dizer de início que elas estão inseridas num conjunto devidamente articulado em que sua concepção não pode ser desvinculada de uma função. Por estes termos, toda forma é, na prática, forma e função ao mesmo tempo (SANTOS, 2004).

Não se pode deixar de pensar que as formas espaciais são fruto de estratégias concebidas pelos sujeitos espaciais. São assim classificadas porque estão relacionadas às demandas espaciais que os sujeitos almejam. Nesse sentido, pode-se relacioná-las, trabalhadas aqui na escala urbana, como uma estratégia espacial do Estado, por meio das políticas públicas. Estas últimas são exemplos de como as formas espaciais podem ser desenvolvidas no espaço urbano e são, antes de tudo, uma abordagem do Estado com o intuito de sua organização e controle. A paisagem, como síntese, acaba por ser resultante e condição das práticas sociais do Estado.

Levando em consideração que a relação entre formas urbanas e políticas públicas se dá por meio das ações do Estado, a atividade turística não estaria isenta desse processo, principalmente porque o turismo se vale, claramente, da oferta da paisagem como condição necessária para sua reprodução ampliada. Um dos condicionantes para isso é, sem dúvida, o consumo do espaço, o que o classifica como sendo um "espaço turístico" (RODRIGUES, 1999; CRUZ, 2001). Como corolário, a paisagem turística é nutrida pelo conjunto de formas espaciais que podem ser 
devidamente pensadas pelo poder público como uma maneira de melhor desenvolver o turismo.

A análise das relações entre as formas urbanas e a paisagem urbana e entre o Estado e as políticas públicas de turismo é necessária para se compreender como a política turística de Estado interfere na organização do espaço urbano na Amazônia. Esse, portanto, é o principal objetivo deste texto. Para tanto, a metodologia escolhida pautar-se-á na análise, ainda que mínima para as pretensões deste trabalho, dos exemplos que o estado do Pará (Brasil) oferecera nos últimos anos em termos de políticas públicas voltadas ao urbano, mediante os tipos de formas espaciais escolhidas como sendo a síntese daquelas políticas, tipicamente veiculadas em seus dois planos de turismo.

O texto está dividido em três seções, além da introdução e das considerações finais. A primeira parte está assentada na leitura teórica do que seja a forma urbana e de suas principais características. Em um segundo momento, torna-se necessário discutir o papel do turismo como fenômeno que contribui para a organização do espaço geográfico. Ainda neste momento, devem ser ressaltadas algumas ideias que sugerem que a paisagem turística é contemplada por um conjunto de formas urbanas necessárias para o turismo. No último momento, a relação entre turismo e políticas públicas será necessária para entender o papel das formas urbanas na Amazônia paraense por meio de exemplos extraídos de seus dois planos de desenvolvimento do turismo.

\section{O PAPEL DAS FORMAS URBANAS NA ORGANIZAÇÃO DO ESPAÇO GEOGRÁFICO: APORTES TEÓRICOS E CONCEITUAIS}

A análise das formas urbanas requer a utilização de um princípio fundamental à organização do espaço (dentre outros), qual seja o da influência no modo de vida das pessoas e, por conseguinte, no uso que as pessoas fazem daquelas, aqui qualificadas como urbanas. Whitacker e Myiazaki (2012, p. 3) afirmam que as formas espaciais "possuem certa capacidade de influenciar as práticas sociais, tanto quanto estas se apropriam e produzem aquelas”. Nessa relação, pode-se constatar o quanto se torna importante compreender a noção e ideia das formas urbanas não apenas como sendo 
elementos espaciais dados como inertes, mas, sobretudo como integrantes de um complexo jogo social atrelado à produção do espaço mediante as relações sociais construídas.

Compreendendo, também, como as relações sociais constroem as formas e estas as influenciam de forma intermitente e sincronicamente, a cidade se torna, assim, um ponto de referência analítico desse processo. Por esses termos, o contexto em que se analisa uma cidade está relacionado ao modo de produção capitalista, o que acarreta na fragmentação, irregularidade e na produção de múltiplos mosaicos sociais (VASCONCELOS; CORRÊA; PINTAUDI, 2013). Certamente, não sendo imune a este cenário, as formas urbanas podem ser entendidas como resultados desse contexto social.

Ainda no que refere ao debate entre as formas urbanas e uma cidade capitalista, seu processo está pautado em um conjunto de elementos que ora funciona com uma engrenagem do tempo condizente a uma aceleração do uso das coisas, marcando, assim, uma maior presença da técnica, da ciência e da informação (SANTOS, 2008) ou, por outro lado, pode-se perceber como as formas do passado convivem com as formas atuais, marcando o passado e o presente em um mesmo recorte espacial que é a cidade. No bojo dessa discussão, a divisão internacional do trabalho e a divisão social do trabalho contribuem para agregar valores econômicos e sociais às formas urbanas, deixando a cidade exposta ao modo de produção capitalista.

Em trabalho recente, Vasconcelos (2013) faz uso de uma tipologia para compreender como se dão os processos e as formas socioespaciais. Nessa análise, em que pese a maior reflexão sobre os processos, percebe-se como as formas espaciais urbanas estão conectadas aos processos que as compõem e esses obedecem à trajetória histórica do modo de produção capitalista atuando no espaço. Para o autor: "nos processos e formas espaciais em análise pode haver superposições tendo em vista que formas espaciais semelhantes podem ser resultantes de processos diferenciados" (VASCONCELOS, 2013, p. 18). Certamente, em uma atividade como o turismo, as formas espaciais urbanas podem estar superpostas às demais formas espaciais urbanas. Nessa aparente mistura dos usos, há, na verdade, apropriações diferenciadas das formas, cada qual servindo aos anseios dos grupos sociais que as pretendem.

Retomando o trabalho de Whitacker e Myiazaki (2012), cabe situar a discussão que reflete o estudo das formas urbanas, entendido, assim, como a morfologia. Os 
autores salientam que a morfologia urbana não pode se restringir ao estudo das formas, ou, para utilizar uma expressão mais atual, do seu design. Dito isto, percebe-se uma profunda relação entre a forma - sendo o aspecto visível - e o processo. Nesse ínterim, a mutualidade entre o continente e o conteúdo ou aquilo que se refere ao que está dentro ou fora é o que melhor se aplica ao estudo das formas urbanas. Por seu turno, sendo a cidade uma síntese dialética do movimento da sociedade, as formas urbanas, ao mesmo tempo contêm os processos e estes podem impor novas formas. Para aqueles autores, a morfologia (considerando a separação entre forma e processo): “implicaria na descrição geométrica, ou seja, da aparência da forma, ou topológica, isto é da relação de umas formas frente a outras formas" (WHITACKER; MYIAZAKI, 2012, p. 313).

Whitacker e Myiazaki (2012) separam a morfologia urbana da paisagem. Para os referidos autores, o estudo da morfologia é necessário por fazer emergir o plano urbano e seus componentes. Por este motivo, chega-se ao nível da apreensão espacial. Entretanto, os autores deixam claro duas considerações fundamentais para que o caminho metodológico escolhido seja adequado. A primeira delas é a ideia de que o plano não pode ser analisado e compreendido isoladamente dos processos urbanos integrantes da vida de uma cidade, mesmo que uma dimensão do plano suscite uma descrição do visível. Depreende-se disso que não caberia um esforço de análise da paisagem como comumente fazem os urbanistas, pois, recorrentemente, esses profissionais são animados pelo espírito dos desenhos arquitetônicos das formas e dos traçados da "cidade ideal", separando o processo da forma, algo que Lefebvre (1976) e Harvey $(1980,2012)$ já haviam sinalizado como sendo ou o espaço concebido ou absoluto. A segunda consideração se refere aos processos sociais que alimentam as formas urbanas. Nesse sentido, vendo a cidade de um ponto de vista dialético, o movimento dos contrários pode, ao mesmo tempo, considerar a forma como indutora dos processos, bem como estes últimos indutores do primeiro. Consecutivamente, os processos sociais denotam formas espaciais tipicamente urbanas. Nesse caso, só seria possível chegar ao nível da apreensão levando em consideração o modus operandi da sociedade que constituiu suas formas espaciais nas cidades.

Alguns exemplos, mesmo que corriqueiros, são importantes para entender os aspectos até aqui defendidos. Ao se considerar duas realidades distintas de cidades brasileiras como Brasília - capital federal - e Rio de Janeiro, há claras distinções. O 
caso de Brasília é emblemático por sintetizar o peso que o design teve na sua construção. Como não existiam construções humanas antes de sua inauguração, Brasília foi pensada, imaginada ou concebida por profissionais do campo da arquitetura e do urbanismo, notadamente Lúcio Costa e Oscar Niemeyer como seus expoentes mais conhecidos. A cidade, dessa maneira, foi preenchida de animosidade humana posteriormente aos seus traçados no papel. A dimensão concebida foi projetada materialmente sobre o terreno em pleno Planalto Central. Esperava-se, com isso, que a dinâmica social constituinte pudesse acompanhar o raciocínio criado por seus projetistas. Assim, Brasília teve seu plano urbano traçado, o que, bem ou mal, permite compreender sua morfologia e paisagem urbanas.

Da cidade do Rio de Janeiro, deve-se ater, principalmente, à apropriação dos espaços elevados, típicos de sua morfogênese. Os morros dão uma clara dimensão de como a sociedade carioca foi se apropriando desses espaços necessários à sua reprodução social ao longo dos anos. Por sua vez, esta cidade guarda uma peculiaridade urbana por reunir em um mesmo horizonte a riqueza e a pobreza ou luxo e a opulência. Em uma mesma zona espacial dessa cidade, por exemplo, pode-se avistar formas espaciais - prédios de bairros como Copacabana, Ipanema ou Leblon - cujo preço do metro quadrado está entre os mais caros do Brasil e, ao mesmo tempo, os morros significando uma ocupação de baixa renda (SILVA et al. 2013), que fora se apropriando conforme a necessidade vital lhe impusera. Nesse caso, os processos históricos constituintes de diversos contextos urbanos (alguns, inclusive de alcance nacional) fizeram com que as formas espaciais fossem um resultado das condições humanas até então constituidoras daquela realidade.

Os casos representativos do Rio de Janeiro e Brasília muito se relacionam com as ideias de Holanda et al. (2000). Focando a cidade de uma perspectiva da arquitetura (sem, no entanto, ater-se ao mero aspecto do desenho) esses autores compreendem a cidade como uma "entidade material”. Nessas condições analíticas, os elementos presentes em uma cidade desencadeiam relações materiais, o que implicaria dizer que os limites do espaço urbano ou tudo o que o cerca seriam definidos pelas formas urbanas (aqui, a ideia de forma acompanha o caminho trivial de afirmar que ela é o resultado do visível ou o dado concreto). 
Ainda Holanda et al. (2000) consideram a forma urbana como produto da organização social de uma cidade. Portanto, poder-se-ia admitir que para se conhecer uma cidade deve-se conhecer seus sistemas de representação grafados em sua base material. Entretanto, os mesmos autores não se desvinculam da ideia de movimento, ou seja, de que as formas espaciais urbanas não poderiam ser interpretadas como um "dado em si”, como se fossem isoladas em relação a uma engrenagem que as alimenta. Sejam nos grandes centros urbanos ou nos pequenos, as formas urbanas produzem ou são reflexos das desigualdades sociais, isto porque o movimento do capital condiciona esse processo contraditório, mas, ao mesmo tempo, organizado (LIPIETZ, 1988). De acordo com essa perspectiva, na condição de pesquisadores desse assunto, segundo eles, devese reconsiderar todo o arsenal de pesquisa sobre uma cidade ou sobre os fenômenos que a acompanham. Atividades como classificar, descrever, analisar, sistematizar e representar passam a ter um bom desempenho se houver a devida inserção das diversas formas de compreender uma cidade. Assim, as categorias espaço e sociedade ganhariam mais autonomia nos estudos urbanos.

Esse poderia ser um caminho a ser adotado ao se comparar as formas urbanas das cidades anteriormente citadas, ainda mais se houver uma disposição analítica que as relacione. As desigualdades sociais, como foram descritas anteriormente, não necessariamente estão na aparência, como se pode perceber - inicialmente - no caso do Rio de Janeiro, mas podem ser ocultadas como no caso de Brasília. Para ambos os casos, a escala do fenômeno urbano é que marca o tom da análise e, ao mesmo tempo, revela os conteúdos do movimento que as cidades imprimem.

As formas urbanas também podem ganhar outros significados se, assim, forem tomadas por outro prisma de análise. No entanto, há a certeza de que as formas espaciais são diversas assim como são os olhares lançados sobre elas. Não tratando especificamente do tema formas urbanas, mas considerando o fenômeno da visibilidade espacial, Gomes (2013) apresenta os elementos inseridos no espaço geográfico a partir do que ele denomina geografia da visibilidade. No que se refere às formas espaciais do turismo, esse assunto muito tem a ver, pois os objetos espaciais criados pelos agentes promotores do turismo se esmeram em dois aspectos importantes relacionados a sua dinâmica: a estética e a funcionalidade. Em ambos, parte-se de uma forma ou de outra, 
dos aspectos constituintes da visibilidade das coisas e, para isso, dependem de como as formas espaciais foram pensadas e executadas para os fins turísticos.

Ao situar o olhar das pessoas sobre o espaço, Gomes (2013) afirma que:

[...] as imagens que conseguem prender nosso interesse estabelecem para si um campo de visibilidade privilegiado. Ao mesmo tempo, essas imagens, objetos centrais de nossa atenção, tornam as outras desinteressantes ou despercebidas, ou seja, paralelamente se estabelece um campo de relativa invisibilidade. Assim, existem aquelas imagens que, por conseguirem se extrair do fluxo da continuidade, se singularizam; mais do que percebidas, elas são individualizadas e recebidas com destaque (GOMES, 2013, p. 6).

Quando se considera o turismo como um fenômeno que não se espacializa por completo no espaço, mas, ao contrário disso, seleciona alguns pontos espaciais, tomados, inclusive como "pontos turísticos" (literalmente), Gomes (2013) tem razão ao estabelecer o jogo dialético entre o que seja visível e invisível. Os pontos turísticos, sobretudo, necessitam visibilizar imagens turísticas, pois estas trazem o poder dinamizador desse serviço em sua essência. Assim o feito, as formas espaciais criadas pelo homem ou reinventadas a partir de um dado natural (como é o caso de cachoeiras, cânions, ou um pôr do sol) conseguem tornar interessante uma parte do espaço. Daí, o poder singularizante do qual o autor chama a atenção. Mais uma vez, percebe-se o quanto se torna importante a compreensão das paisagens por meio das formas espaciais, aqui, especificamente, as urbanas. Gomes (2013, p. 7) ainda arremata: "algumas imagens se impõem sobre outras e parecem legitimamente gozar do direito de ofuscar as demais".

Sob o aspecto da forma espacial de uma cidade, por exemplo, pode-se relacionar a presença de um turista com o lugar a ser visitado. Se para Gomes (2013) o lugar cria o efeito visível-invisível, para Urry (2001) o lugar é transformado pela ótica do turista; é o que ele chama de olhar do turista. No processo de interação entre o turista e o lugar diversas instâncias espaciais aparecem como sendo, ao mesmo tempo, a condição dessa interação e o suporte para ela. Das formas espaciais de uma cidade, pode-se entender como o turismo funciona, não sendo, obviamente, o único modo de compreensão desse fenômeno ${ }^{1}$. No entanto, para que haja um melhor entendimento de como as formas

\footnotetext{
${ }^{1}$ Muitos autores que escrevem sobre turismo e assuntos correlatos, admitem que há diversas formas de práticas turísticas, não sendo elas exclusivamente ligadas ao turismo de massa. No entanto, há quase um
} 
espaciais urbanas produzem um efeito sobre o espaço turístico, faz-se necessário um retorno ao debate do turismo e da organização do espaço como um caminho coerente nesse discurso, tema da segunda seção deste trabalho.

\section{TURISMO E ORGANIZAÇÃO DO ESPAÇO: OS SISTEMAS DE OBJETOS E DE AÇÕES TURÍSTICAS NA COMPOSIÇÃO DAS FORMAS ESPACIAIS URBANAS.}

Tratar da organização do espaço pelos objetos espaciais significa, para começo de discurso, ater-se a algumas características fundamentais para a compreensão do que venha a ser a interferência dos objetos espaciais na produção do espaço turístico. A primeira delas se assenta na tomada de um pensamento voltado para a não neutralidade científica, como afirmara Harvey (1981). Nestes termos, deve-se entender o processo de humanização que envolve a criação dos objetos, independentemente de sua escala ou finalidade. Nesse primeiro processo, portanto, considera-se que toda a produção de objetos é uma produção humana e com determinado sentido. ${ }^{2}$

A segunda consideração reside no fato de que os objetos são provenientes das coisas. Por estes termos, os objetos, por serem humanizados, são parte sequencial do processo de transformação da natureza. Às coisas, caber-se-ia afirmar que o dado bruto é mais recorrente. Santos (2004) é enfático ao dizer que as coisas se tornam objetos porque houvera, nesse ínterim, a utilização de uma dada técnica que os moldou. Como a técnica é parte do processo de (sobre)vivência de uma sociedade (SILVA; MALHEIRO, 2005), torna-se mais evidente considerar o poder que a técnica tem ao tornar uma coisa um objeto. Isso não quer dizer, necessariamente, conforme as ideias dos dois últimos autores, que em uma atividade como o turismo, sejam construídos espaços para a sobrevivência do turista. Diferente disso, os espaços criados possuem como finalidade o lazer.

consenso de que, independentemente, do tipo e da finalidade turística, as pessoas necessitam dos aportes urbanos para facilitar a circulação de pessoas, mercadorias e ideias.

\footnotetext{
${ }^{2}$ No caso da atividade turística, muitos objetos espaciais estão relacionados à classe social para a qual se destinam. Esse procedimento, ainda que não explícito em diversas situações da sociedade, torna-se claro quando se percebe a circulação de pessoas e o tipo de consumo nos espaços turísticos.
} 
A terceira consideração está relacionada ao contexto espacial e temporal em que os objetos espaciais são criados. Destaca-se, assim, que as formas espaciais servientes aos objetos turísticos possuem um poder de variabilidade no tempo e no espaço. Isso significa dizer que, dada uma atividade turística específica, muitos objetos espaciais podem servir para o seu bom funcionamento, mas, em outro contexto, os mesmos objetos podem ser inertes. Um exemplo relevante a ser tomado são os objetos técnicos criados para o chamado "ecoturismo". Para uma realidade não urbana - considerandose, sobretudo, a potencialidade ecoturística de um lugar, os objetos espaciais podem ser muito bem aproveitados; do contrário, em atividades tipicamente urbanas aqueles mesmos objetos podem ser desprezíveis ou incoerentes.

Como no modo de produção capitalista o processo de reinvenção das coisas e dos objetos é mais acelerado, há diversas situações que passam a ter novas significações, podendo ser aplicadas ao turismo. A partir da prática da atividade turística, o espaço tende a sofrer mudanças bruscas, que estão de acordo com uma ordem do capital. Os objetos espaciais do turismo, por excelência, são objetos de grandes transformações espaciais, mediados por ações de agentes do capital e também pelos turistas. O turismo se torna, com isso, um importante veículo de produção de espaços. Esses espaços do turismo, não se aplicam apenas no mundo concreto, antes disso, estão dentro do imaginário do turista. No momento em que ele cria uma expectativa de conhecer o outro, sua ligação produz novos lugares, novos espaços, possibilitando, assim, uma maior rapidez no que diz respeito a sua transformação. Tais circunstâncias são ainda mais visíveis quando outros agentes do setor turístico reforçam a ideia do belo, ou ainda, do que seja atrativo.

A produção do espaço imaginário turístico é, para Rodrigues (1999), por exemplo, uma captação do imaginário coletivo na tentativa de uma resposta. Segundo a autora, a mídia é responsável pelo processo de criação da fantasia do espaço turístico a ser visitado. Inventam-se cenários - os mais belos possíveis - nos quais o estímulo está concentrado nas paisagens fabricadas com o que há de melhor. Ainda nas palavras de Santos (2004), a ordem espacial assim resultante é, também, intencional. Com isso, percebe-se a forma pela qual a mídia introduz novos símbolos que entram no jogo dialético da produção de objetos espaciais voltados à expansão da atividade turística. 
Reconhecendo o espaço como aspecto central na análise do turismo, a geografia representa uma importante área de estudos para esse fenômeno, entendendo as relações sociais como componentes do consumo dos espaços, Rodrigues (1999) procura estabelecer parâmetros de análise teóricos e metodológicos para conhecer como ocorre o processo de constituição dos elementos que formam o espaço turístico, a autora se baseia em Santos (1985) para analisar seus elementos fundadores.

Segundo ainda Rodrigues (1999), o espaço do turismo é formado, ao menos, por cinco elementos: o primeiro deles se refere aos 'homens', caracterizados na figura dos turistas. Estes, na verdade, são a própria demanda turística, ou seja, homens e mulheres e também os agentes responsáveis por grandes firmas internacionais ou ainda os agentes de viagens turísticas. Para ela, a demanda turística é originária, na sua maioria, dos grandes centros urbanos, especialmente das metrópoles, onde estão concentrados trabalhadores de classe média e alta, providos de tempo e dinheiro para efetivar seu deslocamento no espaço rumo a um destino turístico. Ao chegarem, os visitantes entram em contato com a população residente do núcleo receptor de turismo. A população local não é um elemento menos importante dentro do espaço turístico (RODRIGUES, 1999, p. 66). Esta relação entre a população viajante (os turistas) e a população residente (população local) nem sempre se dá de forma harmônica, pois o contato intercultural entre os povos provoca algumas rupturas, desencadeando processos de transformação cultural. Tomando-se essa ideia como premissa para compreender uma parte do fenômeno turístico, o movimento dos turistas se constitui como paradigma a partir da massificação das viagens pelo mundo, notadamente, pós-segunda guerra mundial, ao contrário do que afirmam Nakashima e Calvente (2016).

O outro elemento está constituído na figura das 'firmas', responsáveis por toda a produção de bens, serviços de um sistema turístico. A atividade turística está diretamente ligada ao serviço de hospedagem (as cadeias hoteleiras), bem como às agências de turismo, que, de certa forma, também constituem cadeias. As firmas se caracterizam pela promoção da atividade turística usando o marketing para promover o produto turístico a ser comercializado da melhor forma possível. Por esse motivo, elas atuam em redes internacionais (redes globais) especializadas no setor turístico. Suas funções correspondem, sobretudo, a uma ordem geral de uma empresa, ou seja, o serviço que é prestado num país como o Brasil, de certa maneira, é o mesmo prestado 
em um país como a França, por exemplo. Essa situação se torna possível por ocorrer na era da globalização, na qual os mercados estão unificados, independentes de pertencerem a países ricos ou pobres. As ações das firmas ocorrem de forma uniforme no processo turístico. Para Rodrigues (1999), "as novas relações que se estabelecem em escala mundial e local podem desarticular o local do regional e do nacional, ignorandose as fronteiras do Estado-Nação" (RODRIGUES, 1999, p. 66).

Outro elemento do espaço turístico são as "instituições", correspondentes às "superestruturas" (RODRIGUES, 1999, p. 67). Este elemento se concentra nas ações ditadas por órgãos internacionais ou nacionais de promoção do turismo. Órgãos como a OMT (Organização Mundial do Turismo) com sede na Espanha, OMC (Organização Mundial do Comércio), outras instituições como a Embratur (Empresa Brasileira de Turismo, esta, com caráter de instituto) ou ainda, o Ministério do Turismo, são exemplos de agentes sociais que ditam regras e ordenam o espaço geográfico do turismo, a fim de promover a expansão da atividade. Pode-se perceber, então, que as instituições são, em certos momentos, a própria figura do Estado desmembrado nos seus órgãos de planejamento e gestão do espaço turístico. Por outro lado, as instituições correspondem aos órgãos supranacionais que atuam em âmbito internacional.

O quarto elemento componente do espaço turístico são as 'infraestruturas', ou seja, as redes de transporte, comunicações, saneamento básico, coleta de lixo, tratamento de esgoto ou serviço de ajuda aos turistas como as casas de câmbio e a segurança. As infraestruturas são componentes de organização do espaço para o recebimento do turista. "Este elemento que parece simples é bastante complexo, pois seu volume e conteúdo devem estar dimensionados de acordo com a demanda, pelo menos com a demanda atual de um núcleo turístico". (RODRIGUES, 1999, p. 69). Além das infraestruturas serem elementos do espaço turístico, constituem-se em condição fundamental para a fixação do turista no lugar a ser visitado. Não sendo de boa qualidade, os serviços turísticos ficam comprometidos, ocasionando, assim, uma queda na demanda de viajantes. Deve-se ressaltar, também, que a infraestrutura turística, pode estar associada a um espaço voltado exclusivamente para a atividade, desvinculando-se da realidade local, aumentando, dessa maneira, as disparidades socioespaciais.

O último e quinto elemento é o 'meio ecológico'. Segundo Santos (1985): “é o conjunto de complexos territoriais que constituem a base física do trabalho humano" 
(SANTOS $^{3}$ apud RODRIGUES, 1999, p. 69). Refere-se, principalmente, ao meio natural onde estão assentados os outros quatro elementos anteriores. Seria, outrora, o meio ambiente, porém cada vez mais modificado pelo homem. É a natureza primeira sendo cada vez alterada, transformando-se em segunda natureza, onde impera o mundo da técnica, ou tecnosfera (SANTOS, 2004). No caso do turismo, o meio ecológico é cada vez mais valorizado com o chamado turismo sustentável, ou ainda turismo ecológico. A volta à natureza bucólica, com poucas interferências do homem, torna-se um novo "objeto de consumo" do turismo. É uma forma de valorização das paisagens mais exuberantes e que provocam uma sensação de tranquilidade, numa tentativa de atenuar os impactos ambientais gerados pelo turismo de massa. A repercussão espacial do turismo está marcada por um conjunto de formas, funções, processos e estruturas (SANTOS, 1985). Dentro de uma totalidade espacial, os elementos formadores do espaço do turismo ocorrem em conjunto. Dessa forma, não se pode deixar de afirmar que os objetos espaciais do turismo carregam em si características que estão em consonância com o contexto histórico da atividade.

Entretanto, o debate em torno dos elementos espaciais do turismo não poderia ser dissociado da maneira pela qual estes estão configurados em uma cidade, ou, dito de outra forma, do que eles causam ou dão como consequência quando de seus usos. Na atividade turística os objetos espaciais são designados para seus usos específicos de acordo com uma estratificação social a qual está relacionada, diferentemente (é claro) de outros objetos espaciais contidos em uma cidade. À produção do espaço turístico, a segregação socioespacial se torna um conceito sine qua non na análise de sua produção. Esta ideia se sustenta no princípio de que o consumo do espaço turístico não pode ser para todos, havendo, dessa forma, o processo de segregação espacial.

Sposito (2013) contribui de forma bastante sistemática para elucidar os meandros conceituais que cercam o conceito de segregação socioespacial. Ainda que a dimensão do urbano e a escala da cidade sejam os pontos de referência utilizados na análise, é cabível relativizar à atividade turística, pois, como fora defendido anteriormente, esta última se ancora, inicialmente, na cidade (ou pelo menos do que ela representa) para o desenvolvimento de quaisquer modalidades. Para a referida autora, o conceito de segregação socioespacial, a princípio, não reflete o significado dado a este

\footnotetext{
${ }^{3}$ SANTOS, M. Metamorfoses do espaço habitado. São Paulo: Nobel, 1988.
} 
conceito no início do século XX. Àquela época, o conceito trabalhado refletia observações feitas em realidades norte-americanas, decorrentes de estudos feitos pela Escola de Chicago (HARVEY, 2004). Por outro lado, a autora deixa claro que o uso do conceito requer, ao mesmo tempo, um rigor em seu plano teórico e uma aplicabilidade que depende das diferentes realidades e formações socioeconômicas, o que garante ao trabalho do cientista social uma flexibilidade e adaptabilidade no uso dos conceitos. $\mathrm{Ou}$ seja, as realidades podem ser diferentes, mas a essência teórica deve ser mantida.

Dentre as considerações feitas por Sposito (2013) para o debate que encerra a relação segregação socioespacial e centralidade urbana, uma delas interessa bastante aos assuntos que envolvem a produção das formas espaciais voltadas ao turismo. Nas próprias palavras da autora:

\footnotetext{
Parto da ideia de que, ao conceito de segregação, como a tantos outros de natureza geográfica, deve se associar uma escala geográfica de análise, sem a qual sua compreensão fica vaga. Para mim, a segregação se refere à relação entre uma parte e o conjunto da cidade. A partir deste pressuposto, ela se distingue profundamente das ferramentas metodológicas que visam reconhecer áreas de inclusão/exclusão social. Estas colocam cada parcela do espaço urbano em comparação com todas as outras, para compreender a distribuição das condições socioeconômicas num dado conjunto espacial e, ainda, muitas vezes, comparam com os mesmos indicadores várias cidades, trabalhando na escala interurbana (SPOSITO, 2013, p. 63).
}

A partir do momento em que as formas espaciais criadas pelo e para o turismo, em destaque aquelas pensadas para a cidade, apresentam suas finalidades para um grupo social específico - principalmente aquele que tem o poder de circular capital estabelece-se a segregação socioespacial, sendo, portanto, o turismo um de seus agentes promotores e tributário desse processo. É comum as cidades possuírem pontos turísticos que, por sua exuberância, promovem a segregação dos que podem consumi-los dos que não podem. Em diversos casos, por outro lado, o processo da segregação se dá de forma inversa, ou seja, a autossegregação. Esta última se dá a partir dos grupos de turistas usuários de espaços voltados especificamente para uma classe, não se misturando em outros espaços considerados por eles ausentes de atrativos turísticos.

O processo da segregação socioespacial do turismo apresenta, em outra dimensão, outros aspectos que podem fomentar ainda mais a separação dos grupos sociais. Para tanto, o Estado surge como sujeito fundamental, principalmente quando se utiliza de ferramentas ou instrumentos normativos que legitimam a segregação espacial 
turística. Umas dessas ferramentas (senão a principal) são as políticas públicas. Muitas vezes, sedimentadas em documentos - os planos - as políticas públicas podem expressar o papel das formas espaciais e de como elas podem representar o valor que uma atividade turística tem, sobretudo quando espelham ideais urbanos para os diversos fragmentos do espaço. As imbricações entre as políticas de Estado e as formas espaciais caracterizadas nos planos serão tratadas na próxima seção, tendo como cenário o estado do Pará (Brasil).

\section{O PAPEL DAS FORMAS ESPACIAIS URBANAS NAS POLÍTICAS PÚBLICAS DE TURISMO DO PARÁ}

Inicialmente, é necessário apresentar a diferenciação existente entre políticas, programas, projetos e planos. Isso não é um mero jogo de palavras, mas as atribuições conceituais resultam em qualidades específicas. Compreende-se a política como uma diretriz ou espírito político que direciona os programas. Estes últimos têm o poder de organização territorial maior que as políticas, pois possuem objetivos, metas e metodologias próprias. Já os projetos são mais operacionais que os programas. (HALL, 2001). De forma mais direta, pode-se afirmar que os projetos carregam consigo valores intervencionistas, nos quais o grau de apropriação de um território é mais evidente. $\mathrm{O}$ plano, por sua vez, é um documento que pode deixar claro ou não a política de Estado para um determinado fim. Por ser um documento que reúne os princípios da futura intervenção do Estado, pode apresentar ideias a serem organizadas em forma de programas e projetos (HALL, 2001).

Historicamente, o debate sobre as políticas públicas girou em torno do Estado, sendo este o principal agente formulador e executor das políticas, basicamente em todos os setores da sociedade ${ }^{4}$. Tradicionalmente, o Estado se tornou o agente espacial a coordenar as políticas públicas, dando-lhes um caráter quase "exclusivo" (COSTA, 1996, 2015). Entretanto, as finalidades de suas ações não se restringiram (assim como

\footnotetext{
${ }^{4}$ É importante deixar claro que, ao se referir ao Estado como sendo o sujeito principal na formulação de políticas públicas, não significa dizer que isso se dá de forma absoluta no tempo e no espaço. Outros atores da sociedade também são responsáveis por este papel. Aos sujeitos interessados na organização social por meio das políticas públicas, Rodrigues (2013) os chama de atores políticos.
} 
ainda hoje não se restringem) a um controle e/ou organização social, mas, de forma mais ampla, o Estado sempre visou uma organização sócio-territorial. Costa (1996) afirma categoricamente que, independentemente de ser um discurso geográfico, as políticas públicas são, na prática, políticas territoriais, por revelarem ao público sua dimensionalidade material.

Ao retomar o debate sobre o uso e a importância das formas espaciais, pode-se associar esse assunto à formulação das políticas públicas, em destaque, aquelas que promovem a atividade turística como responsáveis pelo desenvolvimento de seu território. Na Amazônia paraense, no ano de 2001, o então governo do estado lançou o "Plano de Desenvolvimento de Turismo do Pará" com uma versão atualizada em 2011, intitulada "Plano Ver-o-Pará" (PARA, 2001, 2011).

Em que pese o grau de intervenção no território paraense, sua metodologia de aplicação e suas metas alcançadas, o plano apresenta alguns cenários de como a atividade turística poderia ser desenvolvida. Nesses cenários - o "ponto alto" do plano a divulgação de imagens de uma Amazônia paraense revela alguns princípios do documento relacionados a uma segmentação social, utilizando-se, para tanto, exemplos de reordenamento do território. As formas espaciais apresentadas sintetizam os valores globais dos grandes centros, relacionadas às peculiaridades da região, tal como apresentadas na figura 1 . 


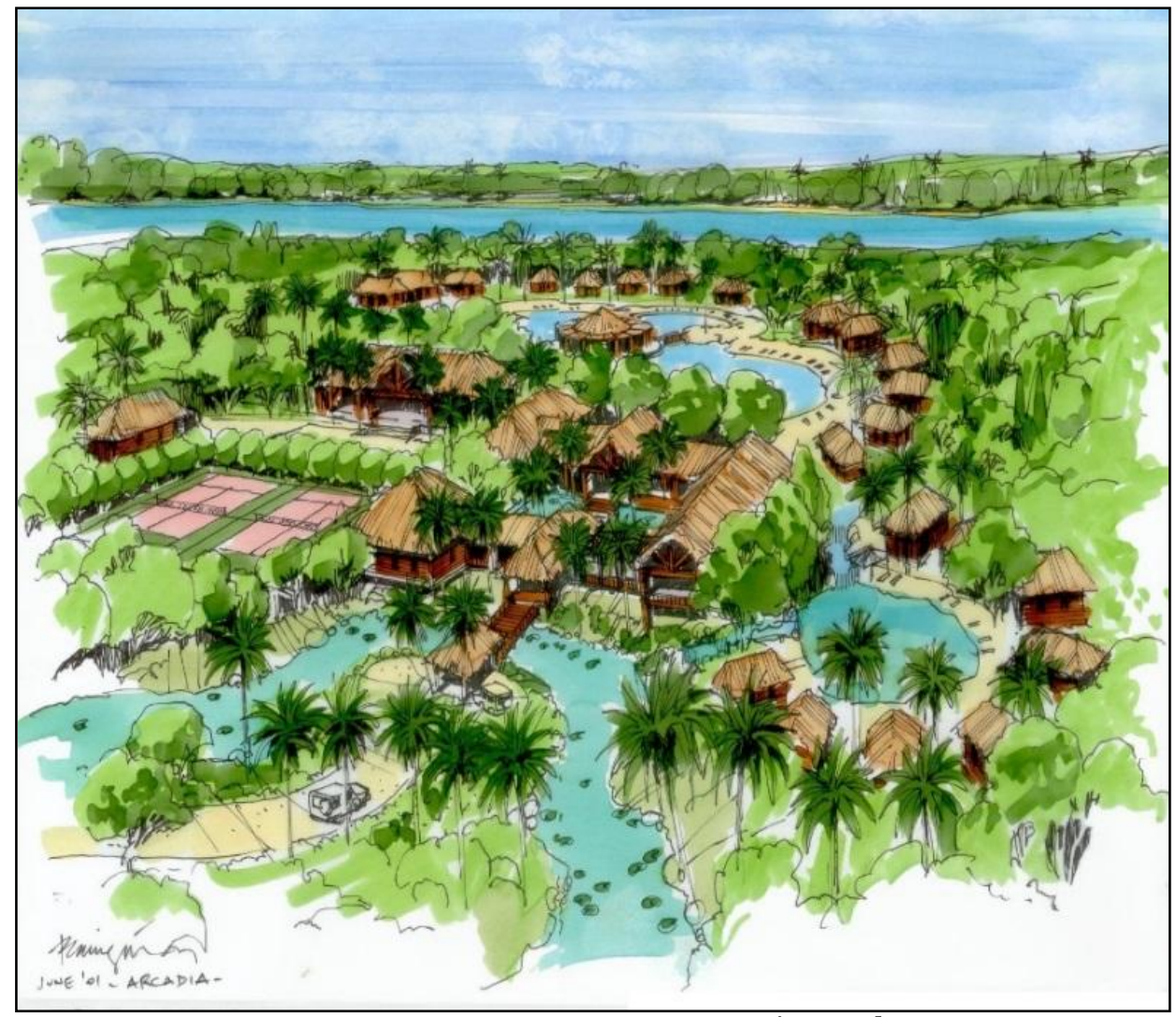

FIGURA 1 - RESORT FLUVIAL E AVENTURA AMAZÔNICA ${ }^{5}$.

FONTE: Pará (2001).

O grau de coesão das formas espaciais contidas no plano de turismo do Pará revela algumas pistas quanto à concepção de turismo e de território do turismo. Antes mesmo de atribuir alguns significados ao tipo de turismo propagado no estado, observase o poder que as formas espaciais têm ao serem utilizadas como meios de confirmação de um tipo de política pública.

A ideia de resort revela um modo de vida urbano em meio à diversidade da natureza. Nesse processo, o convívio com a floresta, por outro lado, apenas serve como uma alusão ao exótico, cabendo às formas urbanas a garantia de uma possível qualidade de uso do serviço turístico. Além disso, o enclausuramento lembra em muito os ambientes urbanos de grandes centros onde a autossegregação é necessária para não haver a interação com outras demandas sociais não usuárias desses serviços.

\footnotetext{
${ }^{5}$ Uma das propostas presentes no primeiro plano de desenvolvimento do turismo do Pará seria a de fomentar a participação de empresas interessadas em criar espaços restritos, de acessos seletivos, tais como os resorts. Na figura 1, as formas imitam uma arquitetura dos povos da floresta, tais como as ocas dos índios ou as casas de ribeirinhos. Uma aventura amazônica, nesse sentido, seria experimentar tudo o que a floresta poderia oferecer, no entanto, de forma simulada.
} 
Esse processo de tomada das formas urbanas, como demonstrado na figura anterior é apresentado ao público em outras passagens do documento de 2001, confirmado pela estratégia de reestruturação da atividade turística no Pará, no ano de 2011. Neste último documento, as estratégias de mercado privilegiam o aumento da entrada de mais turistas no estado. Essas ideias vão ao encontro de um dos objetivos contidos neste último plano, onde há a preferência pela entrada de mais turistas "qualificados" e não aqueles tipicamente associados ao turismo de massa (PARÁ, 2011).

As formas espaciais de turismo assumem o principal papel de atração para maior entrada de turistas. São elas que sintetizam, em grande parte, o que se pode consumir do espaço a ser ofertado. São por elas, também, que se propagam imagens e estas últimas, por sua vez, propagam ideias da forma pela qual devem as pessoas contemplar paisagens e "vivenciar" lugares. Nos planos de turismo do Pará (2001 e 2011) as formas espaciais trazem consigo fortes valores de um tipo de sociedade global que se pretende implantar a partir das metas e objetivos traçados. Nesse processo, a dimensão urbana ora é explicitada por conta do peso dos serviços mais "dinâmicos" - típicos dos grandes centros - ora está velada, ocultada nos valores naturais comuns da Amazônia. A figura 2 é uma representação espacial, contida no plano de turismo de 2001, bem ilustrativa do raciocínio até aqui defendido: 


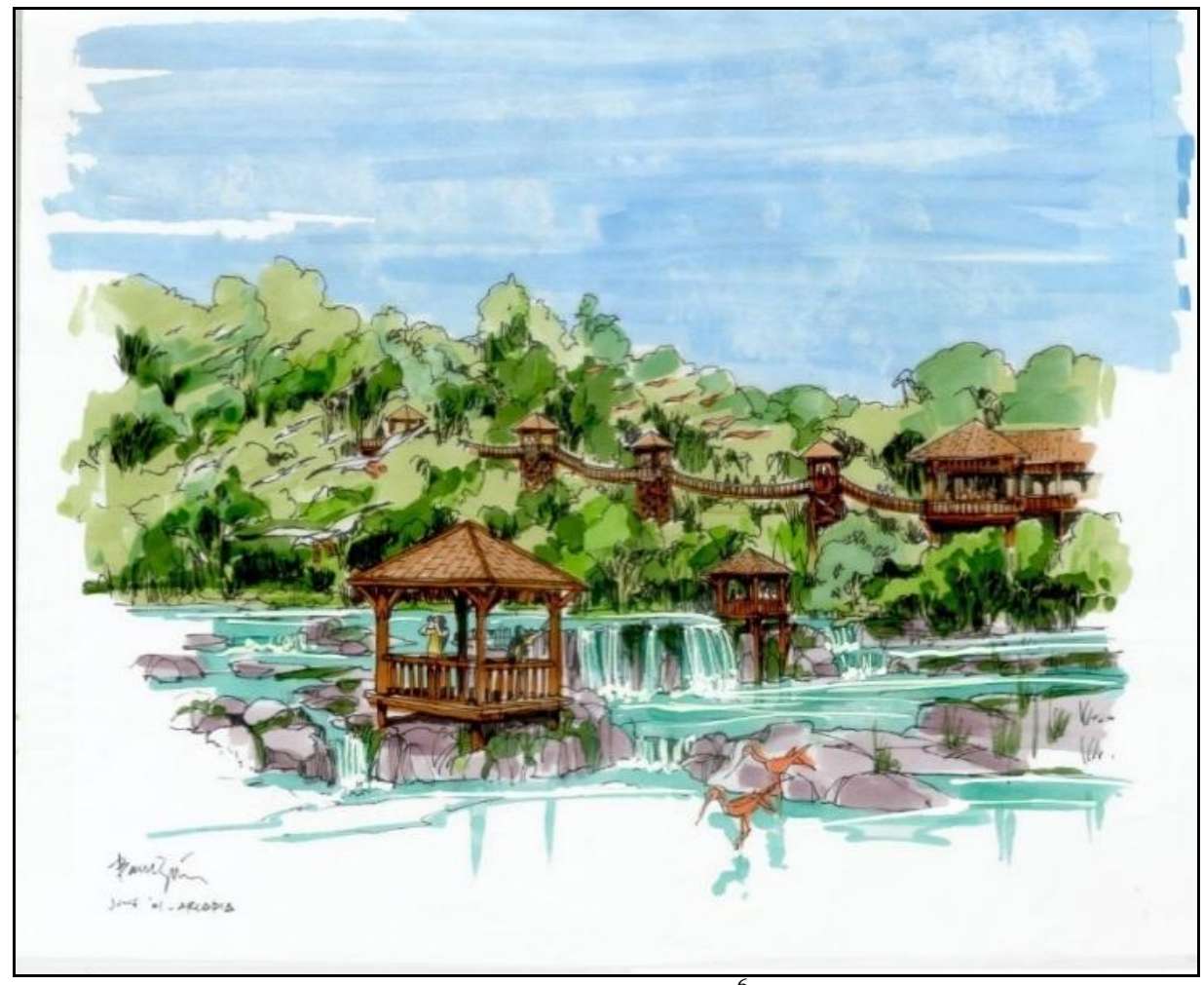

FIGURA 2 - RESORT AVENTURA E NATUREZA ${ }^{6}$.

FONTE: PARÁ (2001, p. 71).

Neste documento, a ideia defendida pelo governo do estado, por meio da empresa terceirizada, é a de que, sendo a natureza amazônica exuberante em sua fauna e flora, deve-se aproveitar a contemplação necessária ao bem-estar daquele visitante da região:

[...] o Plano propõe desenvolver acampamentos ou bases, desde o qual seja possível, fácil e confortável observar, estudar e desfrutar da natureza amazônica [...]. Estas bases, localizadas em lugares pré-selecionados por sua beleza paisagística e riqueza de flora e fauna, devem ser instalações que facilitem, a observação de aves e animais, caminhadas em trilhas, etc. (PARÁ, 2001, p. 71).

Destaca-se, então, o uso dos objetos espaciais no sentido da viabilização das demandas pelo tipo de turismo concebido pelo Estado. A partir da imaginação, concepção e divulgação desse tipo de atividade, sobretudo quando o Estado toma a frente das políticas públicas, revela-se muito mais um distanciamento da realidade

\footnotetext{
${ }^{6}$ Assim como na figura 1 , na imagem da figura 2 são representadas formas espaciais que simulam integração com a natureza, tais como os bangalôs. Diga-se de passagem, a ideia de natureza difundida por meio dessa imagem, revelaria, justamente, uma simbiose entre as formas construídas e as formas naturais. Nota-se, dessa forma, um exercício do espaço concebido em detrimento do espaço vivido (LEFEBVRE, 1976).
} 
territorial do estado do Pará do que uma aproximação, principalmente no sentido de que apenas um segmento de valores está presente na Amazônia, qual seja aquele em que a natureza é dissociada da sociedade. Tal perspectiva é reforçada de forma sutil no plano de 2011, referente ao desenvolvimento do turismo no território paraense. Nesse sentido, Souza (2011), torna-se um importante ancoradouro crítico desse tipo de visão socioespacial. Para o autor, ideias como essas estão mais relacionadas a um "plano de sobrevoo" da sociedade. O Estado, segundo o autor, comumente realiza esse tipo de sobrevoo porque não consegue se aproximar da realidade espacial. Dessa forma, como não consegue ver os detalhes (considerando-se a história do lugar, seus pressupostos e fundadores), anula a realidade ou a camufla:

\footnotetext{
Considerar as sociedades e seus espaços a partir de uma "visão de sobrevoo" implica analisá-los do "alto" e à "distância". Pois bem: o que significa, de um ponto de vista político, examinar os homens e os grupos sociais exclusiva ou quase exclusivamente "de longe", “à distância"? (...). Significa, essencialmente, emular ou adotar a perspectiva típica do aparelho do Estado (SOUZA, 2011, p. 148, grifos do autor).
}

Considerando o horizonte político de um plano de sobrevoo, quando tomado a partir de uma perspectiva da sociedade, as formas espaciais turísticas, também, revelam intenções políticas. Nesse sentido, as formas espaciais do turismo no Pará traduzem concepções dessa atividade podendo produzir simulações espaciais e, ao mesmo tempo, simulações de um tipo de vida urbano que veicula a sensação de que, em uma região como a Amazônia, estar entre o verde intenso simboliza estar em uma floresta urbanizada, como diria Becker (2013). No mesmo sentido, as formas espaciais urbanas, em destaque aquelas voltadas ao turismo, mostram como funciona a engrenagem da paisagem dos lugares, dando a real sensação de que a visão do conjunto espacial depende da organização de seus elementos constitutivos.

Não obstante, as formas turísticas podem ser potencializadas por meio de intenções promovidas por aqueles que as formalizam. A partir de uma perspectiva em que o Estado assume as prerrogativas das políticas públicas, as formas espaciais podem assumir papel importante na tomada de uma ideia como a do turismo no Pará. Sendo assim, as formas espaciais estão presentes em planos, programas e projetos, todos eles integrantes de políticas públicas. Ao estado do Pará, mesmo se não houvesse uma clareza de que tipo de política de turismo seria adotada, as formas imaginadas pelos 
seus dois planos de desenvolvimento já indicariam uma dinâmica urbana muito comum no que se refere ao trade turístico internacional.

\section{CONSIDERAÇÕES FINAIS}

A formulação de políticas públicas pode muito bem revelar e ocultar significados, valores e intenções para diversos usos e fins sociais, todos eles, querendo ou não, desencadeiam processos de reordenamento do território, visto que não se aplicam políticas apenas pelo exercício abstrato do conceito, como se fossem meras elucubrações. Do contrário, as políticas públicas sempre visam um território, seja qual for a escala escolhida.

Vários são os elementos presentes nas políticas. Como elas precisam tomar corpo para serem melhor compreendidas, as formas espaciais emergem como sendo síntese desse processo de racionalização do território. Muitas delas carregam consigo ideais urbanos, representativos do modo de vida urbano e, sendo o turismo um dos segmentos sociais apropriados pelo Estado, ele pode contribuir de forma legítima, mesmo que seja pelo campo da oficialidade ou formalidade.

No Pará, considera-se que as políticas de turismo vêm mostrando ao longo dos anos recentes como sendo, na verdade, muito mais representantes de um segmento social. Em seus documentos - os planos de turismo de 2001 e 2011 - tratam de um turismo tipicamente de mercado e usam exemplos do espaço concebido (aquele relacionado ao campo das ideias) para divulgar um turismo ideal, usando formas espaciais tipicamente urbanas na tentativa de influenciar o modo de vida das pessoas, portanto, suas perspectivas de turismo.

No que se refere aos objetos espaciais relacionados ao turismo no Pará não há, apenas, o estudo topológico das coisas e, posteriormente, dos objetos. Estes últimos são propositadamente reinventados para que possam dar maior fluidez ao processo de turistificação do território paraense, produzindo como consequência uma segregação na apropriação e uso do espaço.

Por fim, utilizando-se de meios analíticos das ciências do território e, ao mesmo tempo, mirando-se em um prisma político, cabe aos estudiosos das políticas públicas de 
turismo observarem mais de perto como os elementos espaciais presentes em programas, projetos e planos se constituem como estratégias de reordenamento do território. Sendo uma contribuinte desse universo, as formas espaciais, em especial as urbanas, são importantes instrumentos de visibilidade das ideias, pois, de forma desigual ou não, elas permitem que se entenda a origem e o produto final das políticas públicas. Em uma atividade socioeconômica como o turismo, por certo, as formas espaciais não se restringem ao aspecto do visível. Mais que isto, são provas materiais das ideias daqueles que as conceberam.

\section{REFERÊNCIAS}

BECKER, B. A urbe amazônida. Rio de Janeiro: Garamond, 2013.

COSTA, W. O Estado e as políticas territoriais no Brasil. 5. ed. São Paulo: Contexto/Editora da Universidade de São Paulo, 1996 (Repensando a geografia).

Políticas territoriais. In: GIOVANNI, G.; NOGUEIRA, M. Dicionário de políticas públicas. 2. ed. São Paulo: Editora da Unesp/ Fundap, 2015, p. 794-798.

CRUZ, R. Política de turismo e território. 2. ed. São Paulo: Contexto, 2001.

LEFEBVRE, H. Espacio y política: el derecho a la ciudad II. Barcelona: Ediciones Península, 1976.

LIPIETZ, A. O capital e seu espaço. São Paulo: Nobel, 1988.

GOMES, P. O lugar do olhar: elementos para uma geografia da visibilidade. Rio de Janeiro: Bertrand Brasil, 2013.

HALL, C. Planejamento turístico. São Paulo: Contexto, 2001.

HARVEY, D. A justiça social e a cidade. São Paulo: Hucitec, 1980.

População, recursos e ideologia da ciência. Seleção de textos, São Paulo, n. 7, p. 1-35, abril, 1981.

O espaço como palavra-chave. Revista geographia, v. 14, n. 28, 2012, p. 8-39.

Espaços de esperança. São Paulo: Loyola, 2004. 
HOLANDA, F.; KOHLSDORF, M.; FARRET, R.; CORDEIRO, S. Forma urbana: que maneiras de compreensão e representação? Revista brasileira de estudos urbanos e regionais. Rio de Janeiro: ANPUR, n. 3, out./ 2000, p. 9- 18.

NAKASHIMA, S. K.; CALVENTE, M. C. M. H. A história do turismo: epítome das mudanças. Turismo e sociedade, Curitiba, n. 2, v. 9, mai./ago. / 2016, p. 1-20.

PARÁ. Governo do estado. Plano de desenvolvimento do turismo do estado do Pará (PDT-PA). Belém: Companhia Paraense de Turismo - PARATUR; THR - Assessoria em Turismo Hotelaria e Recreação, 2001.

Governo do estado. Plano Ver-o-Pará - plano estratégico de turismo do estado do Pará. Belém: Paratur; CHIAS Marketing, 2011 (Fase II: o planejamento estratégico).

RODRIGUES, A. Turismo e espaço: rumo a um conhecimento transdisciplinar. 2. ed. São Paulo: Hucitec, 1999.

RODRIGUES, M. Políticas públicas. São Paulo: Publifolha, 2013 (Folha explica).

SANTOS, M. Espaço e método. São Paulo: Nobel, 1985.

Metamorfoses do espaço habitado. São Paulo: Hucitec, 1988.

. A natureza do espaço: técnica e tempo, razão e emoção. 4. ed. São Paulo: Edusp, 2004.

Técnica, espaço e tempo: globalização e o meio técnico-científico e informacional. 5. ed. São Paulo: Edusp, 2008.

SILVA, B.; SILVA, R.; ARAÚJO, F, Comportamento do consumidor no mercado imobiliário: atributos relevantes na compra de imóveis no Rio de Janeiro. Rio de Janeiro: Sociedade, contabilidade e gestão, v. 8, n. 2, mai./ago., 2013, p. 6-27.

SILVA, M.; MALHEIRO, B. A face ribeirinha da orla fluvial de Belém: espaços de (sobre)vivência na diferença. In: TRINDADE JR., S.; SILVA, M. Belém: a cidade e o rio na Amazônia. Belém: EDUFPA, 2005, p. 145-169.

SOUZA, M. A cidade, a palavra e o poder: práticas, imaginários e discursos heterônomos e autônomos na produção do espaço urbano. In: CARLOS, A.; SOUZA, M.; SPOSITO, M. (Orgs.). A produção do espaço urbano: agentes e processos, escalas e desafios. São Paulo: Contexto, 2011, p. 147-166.

SPOSITO, M. Segregação socioespacial e centralidade urbana. In: VASCONCELOS, P.; CORRÊA, R.; PINTAUDI, S. (Orgs.). A cidade contemporânea: segregação espacial. São Paulo: Contexto, 2013, p. 61-94. 
WHITACKER, A.; MYIAZAKI, V. O estudo das formas da cidade no âmbito da geografia urbana: apontamentos metodológicos. Revista de geografia e ordenamento do território: Centro de estudos de geografia e ordenamento do território, n. 2, dez./2012, p. 307-327.

URRY, J. O olhar do turista: lazer e viagens nas sociedades contemporâneas. 3. ed. São Paulo: SESC/Studio Nobel, 2001.

VASCONCELOS, P.; CORRÊA, R.; PINTAUDI, S. (Orgs.). A cidade contemporânea: segregação espacial. São Paulo: Contexto, 2013.

VASCONCELOS, P. Contribuição para o debate sobre processos e formas socioespaciais nas cidades. In: VASCONCELOS, P.; CORREA, R.; PINTAUDI, S. (Orgs.). A cidade contemporânea: segregação espacial. São Paulo: Contexto, 2013, p. 17-38.

Recebido em: 23-06-2017.

Aprovado em: 23-07-2017. 